\title{
A história institucional recente da política de patrimônio cultural na cidade do Rio de Janeiro: versões protecionistas, versões empreendedoras.
}

\author{
The recent inst itutional history of cultural heritage policy in the city of Rio \\ de Janeiro: protectionist versions, entrepreneurial versions.
}

João Luiz Domingues ${ }^{1}$

RESUMO

O artigo procura-se interpelar as relações entre a nova gestão urbana e o patrimônio cultural. De forma mais vertical analisar-se-á a história recente das políticas patrimoniais em atividade na cidade do Rio de Janeiro, procurando ilustrar duas fases distintas: a primeira mostra correspondência com as escolhas produzidas pelos institutos de proteção da memória nacional, expressando preocupação com a dimensão do conjunto urbano e paisagístico, incluindo preliminar articulação com a dimensão ambiental. Numa segunda fase, mais recente, a política de patrimônio incorpora alguns dos elementos do marketing urbano e da economia criativa, em flagrante aproximação ao empreendedorismo urbano, tendo em seu esforço final ampliado o cenário de centralismo burocrático que já se desenhava. Pretende-se expor que as alterações em curso na forma representar e agir sobre o urbano, que corroboram para a radicalização do processo de mercantilização das cidades, encontram apoio evidente no campo cultural, em especial no que toca ao seu gestionamento.

Palavras-chave: Políticas Culturais. Patrimônio Cultural. Empreendedorismo Urbano. Insulamento Burocrático. Economia Criativa.

ABSTRACT

This article aims to present the relations between the new urban management and the cultural heritage. The recent history of the current heritage policies of the city of Rio de Janeiro will be objectively analyzed and such will be illustrated in two different phases. The first one shows the choices made by the institutions that protect the national memory, which emphasize concern with the urban and landscape ensemble sphere, including preliminary articulation with the environmental sphere. In a second, more

${ }^{1}$ Doutor em Planejamento Urbano e Regional pela Universidade Federal do Rio de Janeiro/IPPUR. Professor Adjunto I do Departamento de Arte e do Curso de Graduação em Produção Cultural e do Programa de Pós-Graduação em Cultura e Territorialidades da Universidade Federal Fluminense. 
recent phase, the heritage policies embody elements from urban marketing and creative economy, becoming notoriously close to urban entrepreneurship, and making the bureaucratic centralism scenario, which was already building up, its final effort. It is aimed to put that the current changes in the form of representation and action on the urban, which contribute to the radicalization of the city mercantilization process, find clear support in the cultural field, especially when it comes to its management.

Keyword: Cultural Policies. Cultural Heritage. Urban Entrepreneurship. Bureaucratic Insulation. Creative Economy.

\section{Território, nova gestão urbana e as dimensões patrimoniais}

É conhecido que as políticas culturais, ainda que de forma parcial e descontínua no Brasil, vêm pouco a pouco se tornando objeto de preocupação na gestão das cidades, complexificando assim as estruturas de intervenção e ampliando o contingente de atores que atuam em seu campo. Por ter se tornado um universo razoavelmente especializado, pode-se afirmar que as políticas culturais já conquistaram uma certa história, seja em um cenário avaliativo, seja no espaço mais restrito de suas ações propriamente ditas, ou seja, na ênfase que se dá aos modos produtivos da cultura e nas relações entre a memória social e o patrimônio.

Deve-se considerar, entretanto, que as relações específicas deste universo são altamente conflituosas. No universo da cidade, essas intervenções se mostram ainda mais limitadas, na medida em que os processos de regulação territorial determinam várias das condições de realização dos fenômenos ligados à organização da cultura.

Neste sentido, defende-se aqui que a relação dialética entre o território e a cultura produzirá formas bastante específicas para a organização da cultura em relação às práticas sociais na urbe. Em razão disso, o objetivo principal deste artigo é identificar como as políticas referentes ao patrimônio cultural são influenciadas por políticas de regulação urbana que extrapolam limites das gestões culturais.

Pretende-se expor que as alterações em curso na forma representar e agir sobre o urbano, que corroboram para a radicalização do processo de mercantilização das cidades, encontram apoio evidente no campo cultural, em especial no que toca ao seu gestionamento. As mudanças estruturais traduzidas como a fase flexível do capital exigiram um novo modelo de governança das cidades, estabelecendo não apenas mudanças na perspectiva de um planejamento racional, mas uma postura mais ativa das coalizões urbanas na promoção do desenvolvimento econômico das cidades. Este novo modelo de planejamento inaugura uma nova qualidade de léxicos para uma noção empreendedora de cidade, explorando as vantagens locacionais para o oferecimento de bens e serviços e a atração de capitais financeiros (HARVEY, 2006).

Tal projeto tem a cultura como um dos seus eixos fundamentais. A mudança da gestão urbana reposiciona "qualidades únicas" da cidade para destacar-se em relação a outras cidades, sejam as naturais, o complexo arquitetônico existente ou a se construir, seus serviços especializados, sua diversidade e atrativos 
culturais. O processo incorpora ainda uma mudança muito sutil no âmbito da propaganda empresarial e das novas formas de análise do consumo. Com a técnica de branding, os publicitários encontraram uma nova forma de gestão da marca empresarial, transformando com alguma radicalidade as linguagens de propaganda. Se durante o início do investimento em propaganda as empresas focaram nas informações sobre seus produtos, operando sobre a ampliação de mercados consumidores, o branding apresenta como novidade a associação aos estilos de vida, como nexo distintivo para a fidelização e animação constante de seus mercados.

Para o universo da cultura, este novo modelo de regulação urbana orientaria a mercadorização de parte da cidade como uma imagem unitária (City Marketing), a partir da seleção de identidades locais e de um alto controle do uso social do espaço urbano (SÁNCHEZ, 1997), que ultrapassa as condições e o universo mais restrito do que se convencionou chamar de gestão pública da cultura.

Este projeto tem ainda como condição a concentração de investimentos do capital em espaços selecionados da cidade, vinculado a alta seleção de modelos normativos e simbólicos para a manutenção de uma agenda de construção de uma certa imagem de cidade a empreender. Neste sentido, este modelo de construção simbólica urbana invade não apenas a esfera do planejamento, mas também a possibilidade de práticas, usos e economias de modos culturais sob diversas formas estatais de regulação altamente complexas e outras reivindicações sociais que atuam em seus hiatos.

A virada para a nova qualificação da gestão urbana carioca ocorre ainda na década de 1990, com a eleição de César Maia à prefeitura do Rio de Janeiro. Este momento define a preferência do eleitorado carioca por um governo "técnico", baseado em um extenso programa de obras urbanas e no controle das contas públicas na gestão financeira da cidade.

É neste ambiente político que a adoção do empreendedorismo urbano (HARVEY, 2006) na forma de planejamento estratégico ganha força na regulação urbana do Rio de Janeiro. Trata-se de um processo que possibilita inscrever a cidade no mercado mundial de grandes negócios urbanos e habitar o imaginário da reificação da cidade sobre um conjunto de atributos culturais. É justamente deste ordenamento do planejamento territorial que emerge uma nova relação entre a organização da cultura e seus desdobramentos no território.

Quanto à perspectiva cultural do modelo de planejamento estratégico, algumas considerações precisam ser levantadas. Parte das críticas à nova gestão urbanística tem como centralidade as políticas de image-making, que negociam a autopromoção publicitária da cidade em torno de sua vinculação como um culturalismo de mercado. Neste caso, a percepção é de que a cultura, "cujo consumo, na forma de refinamento artístico ostensivo, é a melhor garantia de que o clima para os negócios é saudável" (ARANTES, 2000, p. 29), produz, em última instância, uma subordinação de determinados valores-de-uso a valores-de-troca, aos que conseguem extrair desta negociação seus benefícios exclusivos (ARANTES, 2000).

Para esta extração, a caracterização de um modelo culturalista não pode ser neutro às condições de reprodução urbana. Neste modelo, o estatuto do cultural é tanto um recurso estilístico que auxilia a 
transformação da cidade ela mesma em um certo tipo de capital (em geral, baseado na ampliação de serviços culturais específicos, ou na gestão de sua história patrimonial), quanto um recurso político "recomendável" para a concretização de um consenso entre grupos sociais sobre o ingresso da cidademercadoria em um mercado mundial de cidades. Neste sentido, situar a cultura enquanto recurso do empreendedorismo urbano implica em posicioná-la como uma escolha instrumental em torno de disputas e de estratégias semânticas diversas (DOMINGUES, 2012).

Por óbvio, esta nova forma de gerenciamento das cidades precisará se construir em torno de condições institucionais muito especiais. Uma de suas marcas mais evidente é um tipo muito especial de insulamento burocrático de setores formuladores ou viabilizadores de políticas urbanas (KRÄTKE, 2012). Reservados de quaisquer ferramentas de participação ou consulta popular, estes setores insulados são conformados de maneira a elevar parâmetros técnicos de indução de intervenções urbanas em detrimento de formas comunicacionais de planejamento, sob o pretexto de agilização das ações sobre a urbe. No caso das instituições de patrimônio, seu poder de concessão de licenças para alterações no espaço urbano, de fiscalizador de parâmetros edilícios ou de permanência de capitais fixos colocam-nos como centrais para o andamento de intervenções urbanas mais radicais. Como tal, terão como tendência uma formulação mais pragmática de suas políticas, podendo assim reduzir a indução de políticas mais afeitas à ampliação de espaços de escuta, vocalização e negociação com demandas citadinas.

Neste trabalho pretendo discutir como esta nova forma de gerenciamento empreendedor do espaço urbano produziu uma série de interferências nas políticas patrimoniais da cidade do Rio de Janeiro, especialmente após a década de 2010. Como esforço de síntese, foi feito um estudo normativo do campo patrimonial, percebendo-se duas fases distintas em sua trajetória. A primeira fase mostrou correspondência com as escolhas produzidas pelos institutos de proteção da memória nacional. Estas concepções inundaram as legislações cariocas e o conjunto de sua seleção patrimonial, conectando à legislação urbana elementos de proteção imobiliária e de limitação de gabaritos para a construção civil. Numa segunda fase, mais recente, a política de patrimônio mantém a preocupação imobiliária, mas incorpora alguns dos elementos do marketing urbano, tendo em seu esforço final ampliado o cenário de centralismo burocrático que já se desenhava.

\section{A fase protecionista da polít ica patrimonial no Rio de Janeiro: Corredor Cultural e Área de Proteção Ambiental e Cultural}

A dimensão patrimonial como uma questão urbana na cidade apresenta duas fases dist intas na cidade do Rio de Janeiro. A primeira é a protecionista, que conjuga uma série de políticas urbanas iniciadas já nos anos 1970, aparentemente desconectadas do conjunto das políticas culturais, mas que atuam diretamente na relação entre o patrimônio imobiliário e o conjunto urbano tradutor de experiências de memória da cidade. A segunda, que tem início nos anos 1990 e se encontra em pleno desenvolvimento, procura 
incorporar ao circuito protecionista as características gerais do empreendedorismo urbano dedicado ao universo político-cultural, promovendo mudanças profundas nas políticas de patrimônio do município.

Como sabido, o antigo Distrito Federal perdera sua instituição de salvaguarda e promoção patrimonial quando esta foi incorporada à estrutura administrativa do estado do Rio de Janeiro. Ainda que a trajetória das políticas de memória produzida no âmbito da oficialidade fluminense tenha trazido nuances face às políticas orientadas pelo Executivo federal, não existia nenhuma relação explícita com a dimensão da urbanidade e das formas históricas de ocupação do solo.

Em razão disso, como uma aproximação entre as preocupações dos governos municipais com a degradação dos centros históricos, a concepção urbana do patrimônio toma forma de programa municipal, tendo sido trabalhada em órgãos não dedicados à memória social.

O contexto urbano da cidade do Rio de Janeiro sofria com a "destruição e mutilação indiscriminada de bairros e monumentos importantes para a memória da cidade" assim, "o tema da conservação do patrimônio cultural encontrou, pouco a pouco, espaço em debates e discussões no âmbito da sociedade carioca" (CARLOS, 2008, p. 12).

A elaboração do Plano Urbanístico do Rio de Janeiro (PUB-Rio), em 1977, recomendou "a proteção e a conservação do Centro da cidade", tendo se tornado concretamente uma política com o projeto Corredor Cultural. Iniciado em 1979, o Corredor Cultural é o "Plano de Preservação Paisagística e Ambiental para as áreas consideradas de Interesse Histórico e Arquitetônico localizadas no Centro da Cidade" (RIO DE JANEIRO, 1983). O programa é uma resposta à insatisfação de grupos sociais e associações de moradores "com os destinos dos espaços e da paisagem da cidade" (PINHEIRO, 2002, p. 142), alguns descaracterizados após a mudança edilícia que se sobrepunha aos sobrados da fase colonial da cidade.

Como a prefeitura não dispunha dos instrumentos jurídicos de proteção ao patrimônio - tombamento e tutela -, as questões práticas para sua viabilização impuseram a necessidade de utilização das ferramentas do zoneamento e do uso e ocupação do solo, estas "disponíveis dentro de um órgão mais acostumado a lidar com as estruturas urbanas" (PINHEIRO, 2002, p. 144). Assim, o Corredor Cultural começou "sintomaticamente como um projeto muito mais de planejamento urbano do que de patrimônio histórico" (PINHEIRO, 2002, p. 144).

Somente em 1980 o município do Rio de Janeiro, com a Lei no 166, ganha o primeiro instrumento de tombamento e um Conselho Municipal de Proteção ao Patrimônio Cultural, "no processo de implantação e consolidação do Projeto Corredor Cultural" (MACEDO, 2004, p. 19). Apenas neste momento é possível sinalizar a construção de uma política patrimonial atenta ao aspecto urbana na cidade do Rio de Janeiro.

Ainda assim, estando de acordo com os parâmetros federais da legislação de patrimônio, os registros do período dão conta apenas dos tombamentos materiais, junto ao Registro Geral de Imóveis. Ao traduzir a dimensão patrimonial em uma referência imobiliária, a lei de tombamento funciona como uma medida prévia para a criação do Corredor Cultural, dando ainda amplos poderes ao prefeito de decidir sobre os atos 
de tombamento e destombamento.

Por não contar até então com os instrumentos jurídicos e normativos das políticas de patrimônio (processos de educação patrimonial, legislação de tombamento e tutela compartilhada, investimento na concepção histórica ampliada e multifacetada do território), o Corredor Cultural operou sob um "binômio aparentemente contraditório: "preservação e renovação", apostando na "participação da comunidade que utiliza a área no processo de planejamento" (MACEDO, 2004, p. 15).

Quanto ao processo de seleção dos imóveis a se preservar, o prefeito criou uma Câmara Técnica, que compunha tanto a visão técnica associada aos planejadores urbanos da época, quanto ao sentido simbólico, mais amplo, representada por diversos intelectuais². A Câmara Técnica representou um discurso sobre a preservação do centro da cidade que se mostrava conflitivo com o desejo de parte da administração técnica dos planejadores (PINHEIRO, 2002, p. 146).

Quanto à seleção dos imóveis a se preservar, a escolha empreendida figurou o "sít io histórico da cidade até o início do século XIX" (PINHEIRO, 2002, p. 146). Embora esta escolha afirme o centro da cidade na ausência de influências negras e ameríndias, o processo também privilegiou a resignificação dos grupos sociais ao espaço, de forma a construir um patrimônio não apenas submetido ao domínio da arquitetura e da oficialidade da história, "mas das pessoas que usavam esses ambientes, circulavam nele, moravam nele, trabalhavam nele e nele se divertiam" (PINHEIRO, 2002, p. 146).

O instrumento legal para a preservação do conjunto edificado não supunha as condições da legislação de tombamento, ligadas às edificações isoladas. Percebe-se, assim, a dificuldade em encontrar as formas mais adequadas para a implementação do Projeto tal como a Câmara Técnica havia determinado. A fim de construir um certo grau de continuidade na preservação dos imóveis no espaço urbano, preferiu-se encaminhar, em 1984, um projeto de lei à Câmara de Vereadores, durante a gestão de Marcelo Alencar à frente da Prefeitura do Rio de Janeiro.

A Lei no 506, de 17 de janeiro de 1984, institui a Zona Especial do Corredor Cultural, dividida em subzonas denominadas de preservação ambiental e de renovação urbana, e estabelece as condições básicas para a proteção paisagística e ambiental da área por ela determinada. Quanto às subzonas de Preservação Ambiental, o artigo segundo da lei determina que fossem "mantidas todas as características, artísticas e decorativas que compõem o conjunto das fachadas e coberturas dos prédios existentes na área" e "retirados os elementos que comprometem a morfologia original das edificações". Na subzona de Renovação Urbana, qualquer edificação a ser erguida, reconstruída ou reformada deveria "obedecer a projeto integrado ao conjunto arquitetônico ao qual pertence, respeitadas as alturas máximas determinadas". O Projeto protegeu cerca de 1300 imóveis $^{3}$, estabelecendo duas categorias de edificações; as protegidas, em função da

\footnotetext{
${ }^{2}$ Raquel Jardim, Nélida Piñon, Rubem Fonseca, Sérgio Cabral, Italo Campofiorito, Aloísio Magalhães, Lélia Coelho Frota, Arthur da Távola foram alguns dos integrantes desta Câmara Técnica (PINHEIRO, 2002).

3 Os imóveis selecionados estão distribuídos entre: Avenida Presidente Vargas, Rua do Ouvidor, Rua do Carmo, Rua Sete de Setembro, Rua $1^{\circ}$ de Março, Rua São José, Rua Nilo Peçanha, Rua Gonçalves Dias, Rua do Ouvidor, Avenida Rio Branco, Rua Buenos Aires, Rua Uruguaiana, Praça da República, Rua Frei Caneca, Praça da República, Rua Visconde de Rio Branco, Praça Tiradentes, Largo da Carioca, Rua Treze de Maio, Rua Evaristo da Veiga, Avenida República do Paraguai, Aqueduto da Carioca, Rua dos Arcos, Rua do Lavradio, Rua do Riachuelo, Rua Joaquim Silva, Rua da Lapa, Praça Mahatma Gandhi.
} 
importância histórica e paisagística, e as que precisam ser renovadas (reformadas, demolidas ou reconstruídas).

Neste primeiro momento da política de tombamento patrimonial do município, já está construída, de maneira geral, a relação entre a noção de patrimônio cultural e parte da dimensão imobiliária. Esta inflexão resultaria em uma série de políticas urbanas dotadas de caráter restritivo do uso imobiliário de valor histórico-cultural.

No fim da década de 1980, a prefeitura introduziu o primeiro instrumento urbanístico de proteção de áreas urbanas da cidade (CARLOS, 2008). A experiência no desenvolvimento dos bairros portuários projetou ao Rio de Janeiro, genericamente, os métodos de inventário destinados à conservação dos imóveis. Desta forma, definiram-se as Áreas de Proteção Ambiental (Apa), a partir do decreto nº 7.612, de 19884. Em razão desta formulação, a cidade do Rio de Janeiro torna-se referência em políticas de proteção urbana para outros municípios do Brasil (CARLOS, 2008).

Em 1992, as Apas sofrem uma alteração importante em seu aspecto conceitual. O Plano Diretor Decenal da Cidade do Rio de Janeiro, discutido entre poder público municipal e grupos sociais organizados, passa a considerar em seu texto a extensão do princípio de conservação "ambiental" para a conservação do "ambiente cultural", "sinalizando na direção da consideração dos aspectos imateriais existentes na Apa" (CARLOS, 2008, p. 100). Reafirmando a preocupação da Prefeitura com a preservação do conjunto urbano e paisagístico que expressa as diversas fases de ocupação espacial da cidade, emprega-se um novo instrumento urbanístico, as Áreas de Proteção do Ambiente Cultural (APACs). A evidente imiscuição entre os ambientes urbanos integrados à morfologia da cidade e as perspectivas de proteção de áreas de conservação ambiental procurava compatibilizar os limites de crescimento e renovação com as necessidades de proteção patrimonial, incluindo a valorização e proteção da paisagem (RIO DE JANEIRO, 1992).

É possível criticar a relação mais orgânica entre história e memória urbana pretendida pelo conjunto normativo presente nas APACs. O ato de preservação deveria ser capaz de narrar a multiplicidade de ocupações do tecido urbano, não apenas preservar alguns "pedaços do Rio atual que resistiram às brutais transformações impostas à Cidade e mantêm-se carregados de conteúdo, contando aos cidadãos a trajetória de sua sociedade e compondo sua memória coletiva" (CARLOS, 2008, p. 101). Ainda que em seu estatuto de criação o programa fizesse referência à proteção, recuperação e valorização do patrimônio cultural e do ambiente urbano, o que configura clara dimensão estruturante de uma política de patrimônio cultural afeita à integração comunitária, a gestão das APACs 5 pareceu mais preocupado em "controlar o adensamento e o crescimento desordenado e/ou a degradação urbana de bairros da cidade", transformando-se mais em um

\footnotetext{
4 É importante ressaltar que a Apa já "era um instrumento originalmente previsto na legislação federal para a proteção de ambientes naturais que foi adaptado aos propósitos de proteção de áreas urbanas, através de Decretos do Poder Executivo Municipal" (CARLOS, 2008, p. 100).

5 Entre 1990 e 2007, foram incorporadas como APACs as áreas do Bairro Peixoto, Lagoa, Cidade Nova e Catumbi, Cosme Velho e parte de Laranjeiras, Catete, Fábrica Confiança (Vila Isabel), Lido (Copacabana), Cruz Vermelha (Centro), Santa Cruz, São Cristóvão, entorno do Colégio Militar (Tijuca), entorno das Casas Casadas (Laranjeiras), Jockey Club, Teófilo Otoni (Centro), Ribeiro de Almeida (Laranjeiras), Paquetá, Entorno da Igreja do Divino do Espírito Santo (Estácio), Leblon, Laranjeiras, Jardim Botânico, Botafogo, Ipanema, entorno do Colégio Bapt ista (Tijuca), entorno do Mosteiro de São Bento (Centro), Humaitá.
} 
instrumento edilício de "limitador de gabaritos de altura" (CARLOS, 2008, p. 101).

Com todas as críticas que são inerentes ao processo, esta primeira experiência, entendida como uma gênese das políticas de patrimônio cultural especificamente urbanas do Rio de Janeiro, constrói as condições de negociação entre os grupos culturais, o Executivo municipal e o mercado imobiliário. Interessa ilustrar como as relações entre legislações urbanas e perspectivas normativas do patrimônio cultural incluíram a perspectiva de proteção de conjuntos e paisagens. De certa forma, já está aqui concebida uma parte da agenda que irá operar as políticas urbanas de décadas posteriores: a preocupação com os investimentos na Zona Portuária; o vínculo entre cultura, território e meio-ambiente; a paisagem urbana como um condicionante para a dimensão institucional das políticas.

\section{Transição ao Empreendedorismo Urbano carioca}

Como já mencionado e posto de maneira geral, o urbanismo empreendedor se caracteriza por incluir dimensões culturais para habilitar-se. Parte destas dimensões encontram correspondência nas imagens construídas em torno do projeto de cidade e nos discursos que unem as intervenções materiais ao consumo do espaço. Esta arena, cujo norte político da administração pública é dado pelo investimento privado (VAINER, 1999), tem implicações para o conjunto das políticas públicas orientadas ao espaço urbano.

As relações entre território e cultura sob influência da nova gestão urbana também serão a medida da segunda fase das políticas patrimoniais da cidade do Rio de Janeiro. Para afirmar-se como modelo hegemônico, a mercado-técnica exigida pela gestão empreendedora acolhe o campo cultural de forma seletiva. Se a relação dialética entre cultura e território se demostrara capaz de exercer um determinado padrão de preservação de conjuntos urbanos em relação à pressão imobiliária, esta relação se modificará posteriormente.

Este vínculo mais recente do empreendedorismo urbano com as políticas culturais apresenta dois momentos distintos. No período César Maia, entre 1993 e 2008, o invest imento é diretamente conectado ao marketing urbano aplicado ao espaço construído. No período Eduardo Paes, a partir de 2009, este movimento é complementado pela aproximação da economia criativa e por mudanças estruturais na gestão patrimonial da cidade.

O processo é bastante insólito quanto à trajetória. Neste período, as políticas de proteção da década de 1980 já aparecem consolidadas e em plena expansão, em especial na produção das APACs. Para capturar o curso desta relação, que em última instância implica no investimento na imagem urbana como uma medida essencial à preparação da cidade para os megaeventos, o trabalho pontua as linhas principais que estruturam os planos estratégicos produzidos no período: Rio Sempre Rio (RIO DE JANEIRO, 1996); As 
Cidades da Cidade (RIO DE JANEIRO, 2004); e Pós-2016, o Rio mais integrado e competitivo (RIO DE JANEIRO, 2010).

Esta escolha é feita por acreditar-se que estes documentos sintetizam o padrão de intervenção no espaço e sua articulação com o campo cultural. Portanto, a ilustração dos conteúdos destes planos sinaliza a dimensão mais evidente da publicização dos parâmetros do empreendedorismo urbano para a comunidade política. Quanto à política patrimonial, deve-se esclarecer que esta é lembrada pelos planos estratégicos apenas de forma episódica e bastante restrita, em geral reproduzindo a preocupação com o estado do conjunto imobiliário já preservado por legislação. Estes são os parâmetros de uma nova forma de agir na relação território/cultura nas políticas culturais, implicando posteriormente em uma certa mercantilização dos fundamentos patrimoniais, que incidirá na mudança dos rumos de sua gestão na década de 2010.

O período em que César Maia esteve à frente da prefeitura do Rio de Janeiro é definidor para a transição da gestão pública de cultura. No caso das políticas culturais empreendidas no âmbito da municipalidade carioca nas últ imas duas décadas, esta relação se coloca sob uma ordem bastante complexa de ações, por vezes contraditórias, quando se submetem de forma explícita à conjuntura do empreendedorismo urbano. É também a partir da gestão de César Maia que a relação mercantil da cultura com o território é construída mais detidamente, em geral apoiada em iconografias urbanas espetaculares e acessórias ao marketing urbano carioca.

Entretanto, a formulação das políticas culturais deve ser enquadrada em um âmbito geral da gestão urbana iniciada no primeiro governo César Maia. Em 1995 é apresentado, com orientação de consultores catalães da empresa Tecnologies Urbanes Barcelona S.A. (TUBSA), o primeiro plano estratégico da cidade, Rio Sempre Rio.

O texto introdutório do Plano é bastante habilidoso em apresentar as condições gerais de organização urbana do capitalismo financeiro como um dado aparentemente natural, em um contexto urbano no qual emergem "cidadãos cada vez mais exigentes quanto à qualidade de vida urbana". Destaca que "a competição entre países e entre cidades passou a ser de fundamental importância para seu desenvolvimento" e que "os responsáveis pela construção das cidades - sejam eles os administradores, sejam os cidadãos - são chamados ao desafio de intermediar a lógica do mercado e a lógica da cidadania" (RIO DE JANEIRO, 1996, p. 18).

Consta no relatório um objetivo central: tornar o Rio de Janeiro uma metrópole com crescente qualidade de vida, socialmente integrada, respeitosa da coisa pública e que confirme a vocação para a cultura e a alegria de viver. Uma metrópole empreendedora e competitiva, com capacidade para ser um centro de pensamento, de geração de negócios para o país e a sua conexão privilegiada com o exterior.

O dado mais relevante para a discussão do artigo é o acionamento do marketing urbano como uma estratégia de posicionamento internacional da cidade. A Estratégia 7 da "única metrópole-resort do mundo" (sic) previa que o Rio de Janeiro desenvolveria uma série de projetos com "efeitos sobre a sua imagem interna e externa, de modo a se tornar um polo de atratividade regional, nacional e internacional" (RIO DE 
JANEIRO, 1996, p. 51).

Ressaltando que o Rio tem "na sua imagem, um ativo valioso e elemento decisivo para seu desenvolvimento", o Plano afirma a necessidade de uma "maior coordenação entre os vários níveis de governo e melhor relação governo-iniciativa privada" (RIO DE JANEIRO, 1996, p. 51). O diagnóstico indicou a "necessidade de se desenvolver um esforço de marketing", tendo entre as ações a promoção de um mercado de produção e consumo de bens culturais no Centro da cidade; a transformação urbanística da cidade; melhoria dos seus serviços para sua candidatura como sede dos Jogos Olímpicos de 2004; e a criação de diferenciais de atratividade turística, através de megaeventos, programas de qualidade total e corredores turísticos.

Mas a ação central da Estratégia é o objetivo Marketing da cidade. Nela, o Plano pretendia redefinir a sua imagem e criar um "Produto Rio", através de um Plano Cooperativo de Imagem e de um Plano Operacional de Marketing do Rio para atração de visitantes e atividades econômicas (sedes de organizações e associações públicas e privadas). Para o primeiro Plano Estratégico, redefinir a imagem do Rio implicava em "reforçar a atratividade turística e econômica da cidade, definindo, interna e externamente, uma nova imagem com base na identificação dos cidadãos e agentes econômicos e sociais com a mesma" (RIO DE JANEIRO, 1996, p. 51). A aposta é a significação de um modelo unitário de construção imagética urbana, parecendo tornar natural que a reificação da cidade impunha uma imagem reduzida para os que possam consumi-la.

Com vistas a radicalizar a relação entre o market ing urbano e a gestão da cultura, A partir do segundo plano estratégico do Rio de Janeiro, As Cidades da Cidade (RIO DE JANEIRO, 2004), a prefeitura procurou investir de forma mais explícita na viabilização de grandes projetos arquitetônicos em áreas de interesse imobiliário.

A primeira tentativa de indução dos investimentos no espaço urbano através do emprego de capital fixo tem como modelo a experiência na cidade de Bilbao. O município basco passara por um grande processo de desindustrialização e uma crise de suas atividades portuárias após a década de 1980. A aposta na reorganização da economia urbana implicou nas atividades ligadas ao turismo cultural e recreativo. Para tanto, apelou-se ao urbanismo monumental, centrado na "arquitetura de grife" de edifícios-âncora de viés culturalista (BONATES, 2009), via criação de uma filial do Museu Guggenheim.

De maneira a mimetizar o modelo de intervenção urbana da capital basca, já na campanha eleitoral de 2000, César Maia anunciava seu desejo em construir uma filial do Museu Guggenheim no Píer Mauá. A tentativa era tornar o equipamento um impulso para a regeneração do espaço. A iniciativa de implementação da filial Guggenheim na cidade tornou-se, assim, o principal tema de discussão nas políticas culturais no Rio de Janeiro no início dos anos 2000 (CAMARGO, 2011).

Orçado inicialmente em US $\$ 150$ milhões, sendo US $\$ 28,8$ milhões apenas para permissão de uso da marca, o projeto foi muito questionado pelos meios de comunicação, sendo posteriormente suspenso por decisão judicial em 2004, "em resposta a uma Ação Popular gerada na Câmara dos Vereadores, no legislativo 
do Rio" (CAMARGO, 2011, p. 116).

O fracasso na negociação do Guggenheim alterou o direcionamento e o foco do invest imento, mas não sua lógica. Com a formulação do segundo plano estratégico do Rio de Janeiro, as relações entre cultura e marketing urbano se aprofundam, ilustradas no segundo plano estratégico da cidade.

O plano As Cidades da Cidade privilegia a concepção de desenvolvimento endógeno, buscando seccionar o espaço urbano em 12 macro-zonas ${ }^{6}$, tendo cada uma o próprio planejamento, baseado em projetos pontuais que simulavam regiões dentro da cidade (RIO DE JANEIRO, 2004). Mais especificamente na Barra da Tijuca, o plano estratégico introduz mudanças radicais. O "Produto Rio" é substituído pelo "Produto Barra", cuja estratégia definida previa "desenvolver ações que fortaleçam o setor de turismo", tendo como objetivo "melhorar a infra-estrutura e diversificar a oferta de equipamentos e atividades de cultura e lazer" (RIO DE JANEIRO, 2004, p. 65).

Neste âmbito que o segundo projeto de intervenção urbana centrado em um empreendimento cultural espetacular foi concebido, aproveitando a expansão do núcleo urbano, do mercado imobiliário para a Zona Oeste (CAMARGO, 2011). Com execução iniciada em 2004, a Cidade da Música foi projetada em paralelo ao Museu Guggenheim. Findas as possibilidades de implementação da filial na zona portuária, as atenções da prefeitura voltavam-se para a construção de um outro megaprojeto arquitetônico no sítio sub-ocupado da Barra da Tijuca.

O equipamento foi inaugurado, em ato simbólico, em dezembro de 2008, ao final da terceira gestão de César Maia. Quanto ao funcionamento, até a presente data, a Cidade da Música, rebatizada como Cidade das Arte, permanece com portas fechadas ao público, sem clareza sobre seu modelo de gestão.

Esta pequena ilustração dos planos no período César Maia serve para demonstrar que a relação cultura/empreendedorismo urbano constitui uma trajetória já bastante robusta no cenário político carioca. Entretanto, este é ainda um momento em que as legislações de proteção ao patrimônio estão ainda imediatamente conectadas aos limites de gabaritos de construção e de preservação do ambiente construído. De alguma maneira, é possível descrever este momento como de transição para uma relação mais radical na mercantilização do patrimônio cultural.

Durante a primeira gestão de Eduardo Paes, a prefeitura lançou o plano Pós-2016, O Rio mais integrado e competitivo. Este conta com 56 metas e 58 iniciativas, e seu principal objetivo é tornar o Rio de Janeiro uma "referência nacional na excelência do ambiente de negócios com destacada liderança na atração e manutenção de invest imentos produtivos" (RIO DE JANEIRO, 2010, p. 16).

O plano reivindica relações mais estreitas entre o desenvolvimento econômico, a área cultural e o patrimônio. Esta nova relação poderá ser vista nas articulações com a economia criativa e a preocupação

\footnotetext{
${ }^{6}$ As regiões foram divididas em: Campo Grande, Bangu, Jacarepaguá, Barra da Tijuca, Zona Norte, Irajá, Méier, Leopoldina, Ilha do Governador, Tijuca, Centro, e Zona Sul, privilegiando, segundo o Plano, "características histórico-geográficas únicas, habitadas por populações com maneiras de pensar, sent ir e agir singulares, bem como por natureza e topografia dist intas". (RIO DE JANEIRO, 2004, p. 37).
} 
com a paisagem urbana. Ambas as mediações serão componentes estruturais da gestão do patrimônio cultural da cidade.

A referência ao espaço estratégico que a cultura ocupa no desenvolvimento econômico da cidade faz menção a uma "capital líder no desenvolvimento da Indústria Criativa no País, com foco em Design, Moda, Artes Cênicas e Audiovisuais". O tratamento explícito concedido ao campo cultural ainda aparece nas alusões à cidade, reconhecida pela "produção cultural de alto valor e influência mundial", com "destaque pelo respeito à diversidade humana" (RIO DE JANEIRO, 2010, p. 16).

A concepção de economia criativa é tratada como uma novidade no que toca à organização da cultura. Concebida em meados dos anos 1990 pelos governos Britânico e Australiano e adotada por organismos mult ilaterais - Conferência das Nações Unidas sobre Comércio e Desenvolvimento (UNCTAD), a Organização Mundial da Propriedade Intelectual (OMPI), entre outros -, tem sido um parâmetro para o desenvolvimento de um conjunto de políticas voltadas ao incremento de atividades relacionadas ao universo cultural (MIGUEZ, 2007). Seu conteúdo central é, a noção de propriedade intelectual traduzida de forma direta como "patentes, marcas registradas, desenhos industriais, indicações regionais e direitos autorais" (REIS et al., 2012, p. 13), e encontram no cenário urbano vínculos mais estreitos entre a lógica mercantil e o campo cultural.

O Plano Pós-2016 não faz nenhuma menção a dimensões normativas, embora anuncie a centralidade da economia criativa, o investimento inicial mostra o desconhecimento de suas cadeias produtivas. Tendo um alto investimento público, a meta principal da ação é simplesmente "elevar de 2,2\% para 2,75\% o total de pessoas empregadas em atividades da economia criativa, sobre o total de empregados na cidade até 2016" (RIO DE JANEIRO, 2010, p. 192), sem nenhum esclarecimento técnico quanto à definição de sua canastra de possibilidades empregatícias.

Quanto ao diagnóstico da área de resultado Cultura, o texto faz referência a um Rio de Janeiro que sofria com "orçamentos insuficientes voltados para a área, prioridades equivocadas e iniciativas descoordenadas que resultaram em uma área de cultura isolada politicamente". Destaca ainda o invest imento nas obras do Museu de Arte do Rio (MAR) e Museu do Amanhã, ambos equipamentos do Porto Maravilha, retomando iniciativas não concluídas no período César Maia.

Diante deste diagnóstico, o patrimônio cultural é reivindicado como um desafio para o desenvolvimento estratégico da cidade. O texto cita de forma implícita "bairros com oportunidades inexploradas, mas com uma série de atrativos culturais que podem gerar atividade econômica"; "edifícios históricos em mau estado, abandonados ou subutilizados". Entre as metas estão a consolidação da região portuária como local de fomento à cultura, e a valorização da paisagem urbana e do patrimônio cultural do centro histórico através da recuperação e requalificação de áreas relevantes como a Praça Tiradentes e a Lapa".

A iniciativa estratégica Rio Patrimônio-Centro é a que define mais verticalmente a dimensão imobiliária acumulada pelas políticas patrimoniais. Na descrição da situação patrimonial, o plano ressalta 
que o "Rio possui cerca de 22 mil imóveis protegidos pelo município, grande parte deles localizados no Centro da cidade", estando "um elevado número de prédios protegidos pelo patrimônio histórico que se encontram em mau estado de conservação, abandonados ou subutilizados". As ações variam entre as generalizações e as inscrições bastante pontuais: "recuperação de 17 imóveis já considerados estratégicos situados na Praça Tiradentes e na Lapa", ainda que o plano não descreva quais os imóveis estratégicos; "requalificação do espaço público na região", sem que se explicite o entendimento sobre requalificação; "realização de um diagnóstico que inclui a caracterização sócio-econômica da região e a caracterização dos imóveis protegidos do Centro da cidade, identificando a forma de ocupação, utilização e situação fundiária dos mesmos", sem que se descreva o desdobramento desta iniciativa; "revisão dos parâmetros edilícios em lotes vazios"; "realização de editais de concessões para os imóveis definidos como estratégicos"; e "veiculação de uma campanha de promoção e conservação do Centro Histórico".

A aproximação do plano estratégico com as políticas de memória se concretiza na introdução da ideia de paisagem urbana, presente no "alinhamento com as metas da Prefeitura": "Valorizar a paisagem urbana e o patrimônio cultural do centro histórico através da recuperação e requalificação de áreas relevantes como a Praça Tiradentes e a Lapa".

É curioso notar o empenho da administração municipal em dotar o marco da economia criativa como um eixo estrito ao desenvolvimento econômico, ao mesmo tempo em que limita a dimensão patrimonial da cultura ao invest imento em projetos pontuais na área central, os quais complementam a ocupação do solo urbano para grandes empreendimentos funcionais ao período recente de atração de megaeventos na cidade. De maneira explícita, o plano Pós-2016, o Rio mais integrado e competitivo retoma a dimensão da reestruturação urbana do centro da cidade contemplada no plano As cidades da cidade. O investimento nos enclaves urbanos dedicados à atração de negócios rompe com a dimensão de resistência ao crescimento desordenado das políticas de patrimônio imobiliário.

Quanto às políticas patrimoniais, nenhum dos planos faz referência explícita à dimensão imaterial e apenas o Plano Pós-2016, O Rio mais integrado e competitivo apresenta preocupações bastante pontuais quanto à dimensão imobiliária do patrimônio. Esta relação bastante seletiva da dimensão material será melhor problematizada na história mais recente das inst ituições municipais dedicadas ao patrimônio.

\section{A economia criativa e a paisagem urbana}

A história inst itucional do patrimônio cultural ganhará novas mediações ao longo da década de 2000 e 2010. Num espaço de aproximadamente quinze anos a estrutura administrativa reguladora e mantenedora do patrimônio cultural sofrerá uma série de mudanças, até estabilizar suas relações com a lógica do 
empreendedorismo urbano.

A primeira destas mudanças é a transferência das competências do Escritório Técnico do Corredor Cultural para o Departamento Geral de Patrimônio Cultural da Secretaria Municipal de Cultura. (RIO DE JANEIRO, 2000). A segunda é a criação de legislação que dará conta do registro de bens culturais de natureza imaterial que constituem patrimônio cultural carioca (RIO DE JANEIRO, 2003), no esteio da renovação de importância institucional que o Ministério da Cultura, sob a gestão de Gilberto Gil, ganhara em plano federal.

O dado mais relevante do Decreto diz respeito à finalização do processo de inventário. O quarto artigo diz que "O processo de registro, já instruído com as eventuais manifestações apresentadas, será levado à decisão do Chefe do Executivo", e seu \1. ${ }^{\circ}$ afirma que "Em caso de decisão favorável do Prefeito, o bem será inscrito no livro correspondente e será classificado como "Patrimônio Cultural Carioca", sugerindo desde seu nascedouro um alto grau de centralismo burocrático.

Já em 2006, com o Decreto n. 26239, a prefeitura de César Maia altera a Secretaria Extraordinária de Relações Institucionais e cria a Secretaria Extraordinária de Promoção, Defesa, Desenvolvimento e Revitalização do Patrimônio e da Memória Histórica-Cultural da Cidade do Rio de Janeiro (SEDREPAHC), sem alterações relevantes na condução de suas ações.

Em 2009, a política patrimonial sofre nova e importante inflexão, reproduzindo as vidas breves institucionais e suas descont inuidades. O Decreto $n^{\circ} 30.339$, de $1^{\circ}$ de janeiro, tão logo Eduardo Paes assume a prefeitura, incorpora à Secretaria Municipal de Cultura as "funções de Promoção, Defesa, Desenvolvimento e Revitalização do Patrimônio e da Memória Histórico-Cultural da Cidade do Rio de Janeiro, antes exercidas pela SEDREPAHC" (RIO DE JANEIRO, 2009). Desta forma, foi criada a Subsecretaria de Patrimônio Cultural, Intervenção Urbana, Arquitetura e Design (SUBPC).

O decreto modificou a estrutura da instituição de promoção do patrimônio, incluindo as Coordenadorias de Museus e Conservação e Projetos Especiais; além das Gerências de Cadastro, Pesquisa e Proteção; Conservação e Fiscalização; Projetos; Intervenção Urbana e a criação do Centro Carioca de Design. A estrutura da nova secretaria aponta, portanto, para uma renovação dos princípios normativos da concepção patrimonial, destacando a arquitetura, a aproximação com a legislação urbana e, incorporando a dimensão do design como uma das principais áreas da economia criativa.

No caso do investimento no Centro Carioca de Design, a atuação da nova secretaria aponta para a aproximação de elementos do marketing urbano, através da "promoção da política pública para o Design". Esta política tem como foco o "desenvolvimento de uma "consciência de design" (design thinking)", e pretende implementar a divulgação de "ações nacionais e internacionais através de exposições e mostras" para "atrair eventos de grande porte para a cidade" (RIO DE JANEIRO, 2009).

O setor empresarial aparece logo nas palavras-chave da reformulação na instituição como um de seus principais beneficiários. A política pública para o design pretende ainda fomentar "novas iniciativas e parcerias com instituições de ensino e entidades ligadas ao design" como "vetor para melhoria e 
reposicionamento da cidade nos cenários nacional e internacional" (RIO DE JANEIRO, 2009).

A colonização do empreendedorismo urbano na promoção das políticas patrimoniais não se apreende apenas no invest imento mais recente no campo do design, nem em sua descoberta como setor produt ivo da cultura, mas implica também na continuidade da história patrimonial da cidade do Rio de Janeiro. Se durante os anos 1990 e 2000, as políticas municipais de proteção ao patrimônio privilegiaram o aspecto arquitetônico e urbanístico pela introdução do Corredor Cultural e das APACs, a política da nova Secretaria amplia a dimensão do patrimônio para a concepção paisagística-ambiental. Se por um longo período a perspectiva da ação pública sobre o patrimônio se mostrou um foco de resistência à especulação imobiliária, esta nova agenda consegue transformar radicalmente a organização do Executivo, sendo diretamente influenciada por uma dimensão que transcende a gestão cultural.

Esta afirmação pode ser melhor exemplificada quanto à inscrição do Rio de Janeiro como patrimônio cultural da humanidade no World Heritage Committee (Comitê do Patrimônio Mundial) da UNESCO. O Comitê é o fórum deliberativo da entidade que determina, entre outras questões, os locais a serem definidos como Patrimônio Mundial, e a assistência técnica e financeira através do Fundo do Patrimônio Mundial, segundo a Convenção relativa à Proteção do Patrimônio Mundial, Cultural e Natural assegurada aos países signatários (UNESCO, 1972).

O Comitê do Patrimônio Mundial conta com algumas organizações consultivas: o Centro Internacional de Estudos para a Conservação e Restauro dos Bens Culturais (ICCROM), o Conselho Internacional dos Monumentos e Sítios (ICOMOS) e a União Mundial para a Natureza (IUCN). O papel destes órgãos consultivos é avaliar os bens propostos como Patrimônio Mundial, assegurar o acompanhamento do estado de sua conservação, e analisar os pedidos de assistência internacional apresentados pelos Estados.

Em 2002, a cidade do Rio de Janeiro foi apresentada pela primeira vez como candidata, sob a coordenação do Ministério do Meio Ambiente, na categoria sítio misto, natural e cultural, incluindo três fragmentos: o Parque Nacional da Tijuca, o Jardim Botânico e o Pão de Açúcar (BATISTA, 200g). Após a visita da junta da ICOMOS e IUCN em 2002 (UNESCO, 2003), o Comitê indeferiu a inclusão da cidade como sítio misto.

Diante da primeira recusa, a Prefeitura cria em 2004 um grupo de trabalho para a operacionalização da candidatura da cidade, agora proposta sob a categoria paisagem cultural (RIO DE JANEIRO, 2004). A categoria foi incluída no rol do patrimônio mundial apenas em 1992.

O trabalho de produção do dossiê da candidatura contou com as parcerias do IPHAN, Associação de Empreendedores Amigos da Unesco, a Fundação Roberto Marinho, e o Governo do estado do Rio de Janeiro. Em setembro de 2009, o IPHAN protocolou junto à UNESCO o dossiê da candidatura, e em 2011 o Centro do Patrimônio Mundial da UNESCO incluiu a candidatura do Rio de Janeiro na agenda da 36a Sessão do World Heritage Committee.

Até a candidatura do Rio de Janeiro, os "sítios reconhecidos mundialmente como paisagem cultural 
relacionavam-se a áreas rurais, a sistemas agrícolas tradicionais, a jardins históricos e a outros locais de cunho simbólico, religioso e afetivo" (IPHAN, 2011). Contando com assessoria de técnicos da UNESCO (ANDREONI, 2012), a cidade era, portanto, a primeira a se candidatar a Patrimônio Mundial na categoria Paisagem Cultural Urbana.

Na 36a Reunião do Comitê, a ministra da Cultura, Ana de Hollanda defendeu a candidatura da cidade como patrimônio cultural, destacando que esta inclusão "preenche uma lacuna, porque não se pode pensar no patrimônio do Brasil sem visualizar o cenário da cidade do Rio de Janeiro" (HOLLANDA, 2012). O discurso de defesa apresenta considerações sobre o ineditismo da proposta de patrimonialização, "uma vez que se trata da primeira área urbana em uma metrópole inscrita como paisagem cultural" (HOLLANDA, 2012).

A inscrição da proposta Rio Paisagem Cultural levou em conta "áreas exemplares da cidade", circunscrevendo uma seleção reunida "em dois setores articulados entre si pela malha urbana com suas cadeias montanhosas" (HOLLANDA, 2012), compartilhada entre órgãos e legislações da administração federal, estadual e municipal, em grande parte já tombada pelo IPHAN. O primeiro setor selecionado foi formado pelo Jardim Botânico, o Parque Nacional da Tijuca, e o Parque Lage. O outro, mais extenso, levou em conta os elementos do litoral da cidade e selecionou a relação do Parque do Flamengo com o Museu de Arte Moderna e áreas adjacentes (Passeio Público, Praça Paris, Outeiro da Glória); a entrada da Baía da Guanabara e seus morros e fortalezas de leste a oeste, a enseada de Botafogo e o Monumento Natural dos Morros do Pão de Açúcar e da Urca, a praia de Copacabana e suas franjas, morro do Leme, Forte de Copacabana, até a Pedra do Arpoador.

O grau de obsessão por legitimidade patrimonial e especificamente esta seleção respondem às necessidades de publicização de imagens da cidade na lógica da mercado-técnica urbana. De forma geral, estas fazem-se por produções de imagens-síntese de uma realidade urbana parcializada realizadas por algum tipo de trabalhador especializado, com base em estereótipos de morfologias e capitais fixos simplificados ou mimetizados (arquiteturas-grife ou paisagens naturais), e vulgarizações pragmáticas de experiências coletivas da vida social no espaço (DOMINGUES, 2012; SÁNCHEZ, 2010).

Em sendo, a produção de imagens-síntese realiza ainda uma segunda função, confirmando uma visão parcial de mundo adequada à publicização de signos de bem-estar e satisfação orientadas às demandas de consumo e estilos de vida de grupos sociais com capacidade de acumulação de capitais (SÁNCHEZ, 2010). Mas estas experiências de produção de imagens também conformam a dimensão material do espaço, acumulando no cenário urbano marcas que conseguem traduzir expectativas parciais de estilos de vida mundializados. Esta modalidade de espetacularização urbana realiza um certo marco ingresso no rol de urbanidades globais, estimulando "a reinvenção da cidade e sua nova inscrição mundial pela via dos megaeventos ou dos grandes projetos urbanos" (SÁNCHEZ, 2010, p. 17) e fragmentando o tecido urbano em territórios com capacidade de atração de sujeitos e investimentos que possam reordenar o fluxo de consumo cultural.

Tomadas como representações fidedignas e totais da realidade urbana, estas imagens-síntese produzidas em razão de projetos isotópicos dominantes de alteração urbanas "não deixam margem a 
dúvidas ou interpretações diversas sobre a informação que veiculam, não oferecem alternativas à sua decodificação" (SÁNCHEZ, 2010, p. 108). Como fatos sociais inquestionáveis dotados a uma cidade idealizada, este processo de edição da realidade é impeditivo da "possibilidade de existência de outras imagens e de outras leituras" (SÁNCHEZ, 2010, p. 108), impondo barreiras aos sujeitos sociais cujas experiências pareçam secundárias aos parâmetros da cidade empreendedora.

Entre as decisões adotadas na $3^{6}{ }^{a}$ reunião do World Heritage Committee, a inscrição do Rio de Janeiro como patrimônio mundial foi aceita, tendo sido acolhida em dois critérios: um exemplo eminente de implantação humana tradicional, da utilização tradicional do território ou do mar, que seja representativo de uma cultura; e estar direta ou materialmente associado a acontecimentos ou a tradições vivas, ideias, crenças ou obras artísticas e literárias de significado universal excepcional.

No relatório apresentado, o Comitê reconhece que "o desenvolvimento da cidade do Rio de Janeiro tem sido moldado por uma criativa fusão entre natureza e cultura", que se reflete através de um "intercâmbio com base em ideias científicas, ambientais e urbanas que levou a criações paisagísticas inovadoras", "percebida como de grande beleza por muitos escritores e viajantes e que moldou a cultura da cidade" (WORLD HERITAGE COMMITTEE, 2012, tradução nossa). Cita também o fato da paisagem do Rio de Janeiro ser fonte inspiradora para muitos bens culturais, reconhecendo que as imagens da cidade sintetizadas na Baía de Guanabara, Pão de Açúcar e Cristo Redentor "tiveram um fator de grande reconhecimento a nível mundial" (WORLD HERITAGE COMMITTEE, 2012, tradução nossa). Curioso notar como as principais fontes para a candidatura reproduzem os ícones tornados imagens publicitárias ao longo do século XX e início do século XXI.

Quanto à perspectiva da integridade da paisagem, o relatório reconhece que as áreas em torno da Baía se tornaram terrenos com alto valor-de-troca imobiliários e contribuíram para uma cultura "ao ar livre" na cidade. Destaca que nenhum dos ambientes está sob ameaça, embora "a interface entre esses elementos naturais e da cidade construída seja vulnerável a pressões urbanas", em especial a Lagoa Rodrigo de Freitas e as faixas de praia, "sujeitas a um grau de poluição da água" (WORLD HERITAGE COMMITTEE, 2012, tradução nossa).

Com o reconhecimento do Rio como patrimônio mundial, as três instâncias de governo assumiram uma série de compromissos. Entre eles estão a obrigação de assegurar a proteção da área identificada como Patrimônio Mundial, para garantia de sua transmissão às gerações futuras; gestão compartilhada entre as instituições das três instâncias governamentais responsáveis pelo sítio Rio Paisagem Cultural; incremento do turismo cultural, da economia da cultura e do turismo; contribuição para a manutenção do posicionamento da cidade no cenário internacional; entre outros (BATISTA, 2009).

De pronto a responder os compromissos firmados com a UNESCO, a prefeitura do Rio de Janeiro altera radicalmente a estrutura relativa à proteção patrimonial. O Decreto nº 35.879 , de julho de 2012, ext ingue a Subsecretaria do Patrimônio Cultural, Intervenção Urbana, Arquitetura e Design e cria o Instituto Rio Patrimônio da Humanidade (IRPH), retirando-o da Secretaria de Cultura e ligando-o diretamente à estrutura organizacional do Gabinete do Prefeito. 
A prefeitura do Rio de Janeiro atende, assim, a uma das necessidades estruturantes de gerenciamento do empreendedorismo urbano. Recrutando operados que se identificam com a lógica gerencial da administração privada, a organização burocrática é refundada. Neste domínio, "bolsões de gerência técnica" acabam por condensar competências de fontes exclusivas de análise e decisão, em funcionamento operacional realizado sob alto grau de insulamento burocrático, e geralmente vinculados diretamente aos chefes do executivo (RIBEIRO, 2011). As considerações iniciais do decreto reforçam o que havia sido esboçado em 2009. Ao passo em que reconhece que o "patrimônio cultural constitui a consciência que uma comunidade humana possui do próprio viver histórico", afirma também "o potencial do patrimônio cultural, da arquitetura, da paisagem cultural urbana e do design como vetores de desenvolvimento da economia criativa na Cidade do Rio de Janeiro" (RIO DE JANEIRO, 2012). A diferença fundamental é que a atuação do IRPH não responderá ao conjunto mais amplo de produção de políticas culturais, estando pouco afeita à ampliação dos mecanismo de participação como visto em políticas públicas mais recentes.

A explicitude do vínculo do patrimônio cultural como uma das canastras de setores da economia criativa presente no decreto de criação do Instituto Rio Patrimônio da Humanidade sugere algumas dimensões essenciais para compreender como a ativação do marketing urbano e do empreendedorismo urbano consolidou certa maturidade no gerenciamento patrimonial da cidade do Rio de Janeiro.

A forma global de espacialização do capitalismo flexível conecta-se de forma endêmica à atração de sujeitos menos propensos à fixação territorial, tal qual correlação a dispersão financeira atual. Como tal, os interesses destes sujeitos sociais serão consagrados no tom distintivo de reorganização da produção do espaço urbano (o uso do espaço deter-se-á diretamente na estilização da vida destes consumidores ativos) e no apoio ao fornecimento de serviços adequados a um certo tipo de refinamento estét ico orientado (CLARK et al., 2002).

As cidades que contam com dinâmicas menos rebuscadas de produção de sua economia urbana precisarão compor um certo número de propriedades diferenciais, buscando a atração de sujeitos mais interessados no gasto econômico imediato que à fixação territorial (DOMINGUES, 2012). Desta forma, extratos de solo com dimensões ou características ambientais diferenciais, expressões culturais que traduzem qualidades únicas, ou capitais fixos de valor excepcional serão passíveis de apropriação como renda monopolista, cuja função imediata é a criação de sobre-valor à canastra de ofertas de experiências da cidade reificada (HARVEY, 2006).

Nesta condição os limites para a determinação dos preços de uso do solo ou da excepcionalidade de capitais fixos são determinados pelos rendimentos derivados desta propriedade diferencial (no caso, a seleção da paisagem), que não necessariamente se constroem por sua capacidade de fabrico de bens raros, mas pelo direito ao acesso espetacular de usuários solventes.

Esta nova condição exercida em liquidez absoluta pela nova gestão urbana é identificado por Harvey nas classes burguesas indutoras de tipos de rent-seeking (HARVEY, 2006), crescentemente articulado à acumulação rentista via criação monopolistas inclusive ligadas à intangibilidade de marcas urbanas, um certo modelo de branding das cidades. 
O anúncio de parte do Rio de Janeiro como patrimônio mundial tornou-se uma das formas de apresentação da cidade no contexto internacional, alcançando também outros meios de divulgação. Neste sentido, a dimensão do empreendedorismo urbano foi referendada. "O milagre econômico parece ter chegado à cidade Patrimônio da Humanidade e a Câmara portuguesa não está disposta a deixar passar em branco as oportunidades" (LOPES, 2012). É por meio destas falas, ainda que episódicas, que a vinculação entre marketing urbano e políticas de memória fica mais evidente e corrobora a sutil preocupação do decreto em encontrar os lastros do potencial do patrimônio cultural como um vetor de desenvolvimento da economia criativa na Cidade do Rio de Janeiro.

$\mathrm{Na}$ avaliação do setor hoteleiro e de bares e restaurantes o "título inédito reforça a imagem do Rio de Janeiro como destino turístico internacional", e "só vem a somar com o movimento de alta que a cidade do Rio tem vivido" (LOPES, 2012).

O caso do Rio de Janeiro é exemplar para perceber como a perspectiva de atração destas classes e destes capitais incorpora, de maneira correlata, a necessidade de transmissão de ideias novidadeiras de sua gestão (no caso, o vínculo com a economia criativa promoverá um certo alinhamento da cidade do Rio de Janeiro com a generalização de cidades globais e de suas classes mais privilegiadas), estabelecendo rotinas de rendas monopolistas à forma como o patrimônio cultural será administrado.

\section{À guisa de conclusão}

Como ilustrado ao longo deste artigo, a introdução de uma determinada noção de paisagem e da economia criativa é hoje o núcleo das políticas de patrimônio na cidade do Rio de Janeiro. Porém, conforme visto, esta nova faceta das políticas patrimoniais se estabelece na superação de uma fase das políticas urbanas, cuja preocupação central era promover a interlocução entre o patrimônio imobiliário, o conjunto de experiências de memória da cidade, e as áreas dedicadas à proteção de territórios compreendidos como singulares ao ambiente cultural. Esta transição se mostra esboçada já nos anos 2000, mas se completa e radicaliza apenas muito recentemente.

Neste período, foram muitas as tentativas de indução de desenvolvimento econômico com base no empreendedorismo urbano, tendo os planos estratégicos como fonte principal para esta percepção. A primeira é fortemente identificada com o período em que se inicia o projeto para recepção dos megaeventos. Neste momento, embora permanecesse intactas às políticas que privilegiaram o conjunto urbano carioca e a relação patrimonial, a lógica de indução cultural do empreendedorismo é trabal hada sob investimentos em capital fixo espetacular para dotar a cidade do Rio de Janeiro de um certo tipo de capital cultural urbano, com a finalidade de ingressar em um mercado internacional de inovações arquitetônicas. 
Afinada com intervenções urbanas propriamente ditas, a dimensão simbólica requerida nestes planos estratégicos se mostrava redutora dos valores-de-uso urbanos, concentrando a sua seleção em uma fonte imagética capaz de traduzir a experiência urbana em valores comercializáveis. Esta opção traduz a sutil diferença entre o city marketing aplicado ao espaço construído e o city branding.

Como demonstrado, aos limites da política patrimonial e seu acento na preservação imobiliária são incorporadas as preocupações com a inovação e entretenimento disponíveis aos usuários, dimensão requerida pelo plano Rio Pós-2016. Este movimento de colonização, embora novidadeiro, é complementado pela aproximação com a ideia de economia criativa, promotora de profundas mudanças estruturais na gestão patrimonial da cidade. A criação da Subsecretaria de Patrimônio Cultural, Intervenção Urbana, Arquitetura e Design é uma referência explícita a setores exponenciais da economia ligados à propriedade intelectual e à inovação.

Ainda que com vida curta, como apresentado, a Subsecretaria é um exemplo da conexão entre esta noção de criatividade orientada como princípio de desenvolvimento econômico e o acervo normativo para a expansão do capital imobiliário na cidade do Rio de Janeiro. Embora não seja explicitada enquanto tal, a dimensão da criatividade operada no circuito urbano carioca atende ao conjunto de intervenções urbanas acessórias à recepção de megaeventos e do interesse de seus usuários e dos setores capitalistas que deles se apropriam, seja ao proporcionar um conjunto de entretenimentos baseado na inovação, seja por proporcionar uma imagem de cidade cuja condição é a inovação.

A lógica criativa faz menção, no plano estratégico Rio Pós-2016, a intervenções pontuais no Centro da cidade, deslocando o "Produto Barra" para a região central da cidade. O Rio Pós-2016 investe na indução de investimentos em enclaves urbanos, destacando os equipamentos culturais que iniciam a intervenção na Zona Portuária - Museu de Arte do Rio e Museu do Amanhã - e na requalificação da Praça Tiradentes e do bairro da Lapa. É possível sinalizar que esta dimensão das políticas urbanas orientadas pela iniciativa de equipamentos culturais pode produzir um forte processo de gentrificação na área central da cidade, seja na "revisão dos parâmetros edilícios em lotes vazios" ou na "realização de editais de concessões para os imóveis definidos como estratégicos" (RIO DE JANEIRO, 2010, p. 208)7.

Aparentemente, este processo se mostra com tamanha monta e centralidade para a gestão urbana que recentemente incide, ainda, em mais mudanças na organização institucional das políticas patrimoniais. Como relatado, todo o processo descrito na candidatura do Rio de Janeiro junto à UNESCO para declarar a paisagem da cidade como Patrimônio Cultural da Humanidade realiza um nível alto de insulamento burocrático para as ações patrimoniais. Diferentemente da organicidade social vista na confirmação do sediamento da Copa do Mundo e Olimpíadas, o referido título da UNESCO não foi utilizado pela prefeitura para mobilizar a população sobre esta dimensão patrimonial.

Mas a criação do Instituto Rio Patrimônio da Humanidade, e sua vinculação direta ao Gabinete do

\footnotetext{
7 Embora não tenha sido objeto deste artigo, a aquisição de um lote de 43 imóveis na Rua da Carioca - que, entre outros estabelecimentos, sedia o Bar Luiz e a loja de instrumentos musicais Guitarra de Prata - pelo Grupo Opportunity operou um aumento nos contratos de locação.
} 
Prefeito, muda não apenas a estrutura organizacional do atendimento patrimonial, mas descola a inst ituição dedicada ao patrimônio cultural do conjunto mais amplo das políticas culturais. É possível supor que a noção patrimonial ligada ao acervo paisagístico único da cidade do Rio de Janeiro seja tratada, de agora em diante, pelo núcleo decisório mais forte da coalizão urbana, podendo, assim, radicalizar a diferença no tratamento entre as faces materiais e imateriais das políticas de patrimônio.

Se isso ocorrer, serão restringidas as noções mais novidadeiras trabalhadas no âmbito patrimonial - em especial a noção de referência cultural, intimamente ligada às ações sobre o patrimônio imaterial e aos grupos sociais com vínculos mais frágeis em relação à construção de políticas públicas. Como tal, a ilustração da paisagem selecionada para o Patrimônio Cultural da Humanidade já se mostra regida por limitações dos valores-de-uso do território urbano, majoritariamente conectados a uma faixa estrita da Zona Sul da cidade.

Desta forma, as relações entre o empreendedorismo urbano e as polít icas patrimoniais parecem operar sob três facetas: i) a incorporação acrítica da economia criativa, como uma coqueluche categorial em que o urbanismo do Rio de Janeiro torna a cidade cool, compet idora de capitais e sujeitos criativos ou interessados em sua estética inovadora; ii) as imagens derivadas deste processo, baseadas em ritos inovadores, que promovem intervenções no tecido urbano, os quais privilegiam formas estéticas e a presença dos usuários solventes do processo empreendedor urbano; iii) a restrição institucional atual do patrimônio, que acentua a dimensão de uma fração paisagística da cidade em detrimento da ampliação de mecanismos mais evidentes de consulta à patrimonialização, estabelecendo marcas de centralismo burocrático que privilegiam as dimensões materiais das políticas patrimoniais. Tal como desenhado, a relação entre operações urbanísticas, imagética urbana, normatividade político-cultural, e a memória citadina impõe uma série de obstáculos aos grupos ident ificados com a dimensão ét ico-ident itária das políticas culturais.

\section{Referências}

ANDREONI, Manuela. Candidatura carioca a patrimônio mundial contou com assessoria dos próprios técnicos da Unesco. $O$ Globo, Rio de Janeiro, 2 jul. 2012. Disponível em: $<$ http://oglobo.globo.com/rio/candidatura-carioca-patrimonio-mundial-contou-com-assessoria-dosproprios-tecnicos-da-unesco-5376089>. Acesso em: 5 maio 2016.

ARANTES, Otília. Uma estratégia fatal. A cultura nas novas gestões urbanas. In: ARANTES, Otília; VAINER, Carlos; MARICATO, Ermínia. A cidade do pensamento único: desmanchando consensos. Petrópolis: Vozes, 2000.

BATISTA, Márcia Aguiar Nogueira. Candidatura do Rio de Janeiro a patrimônio mundial categoria paisagem cultural. In: SEMINÁRIO DOCOMOMO BRASIL, 7., 2009, Porto Alegre. Anais... Porto Alegre, 2009. 
BONATES, Mariana Fialho. El Guggenheim y mucho más - urbanismo monumental e arquitetura de grife em Bilbao. Pós: Revista do Programa de Pós Graduação em Arquitetura e Urbanismo da FAU/USP, São Paulo, v. 16, p. 62-91, 2009.

CAMARGO, Paula de Oliveira. As cidades, a cidade: política, arquitetura e cultura na cidade do Rio de Janeiro. 2011. Dissertação (Mestrado em História, Política e Bens Culturais) - Fundação Getúlio Vargas, Rio de Janeiro, 2011.

CARLOS, Antônio Santos Lima Carlos. Áreas de proteção do ambiente cultural (APAC): da idealização à banalização do patrimônio cultural - RJ. 2008. Tese (Doutorado em Urbanismo) - Universidade Federal do Rio de Janeiro, Rio de Janeiro, 2008.

CLARK, Terry Nichols et al. Amenities drive urban growth. Journal of Urban Affairs, Malden, v. 24, n. 5, p. 493$515,2002$.

DOMINGUES, João L. P. Marketing urbano e a dimensão da criatividade: colonização iminente do capitalismo flexível?. Revista Latitude, Maceió, v. 6, n. 2, p. 191-217, 2012. Disponível em: $<$ http://www.seer.ufal.br/index.php/latitude/issue/view/84>, acesso em 08 de agosto de 2013.

HARVEY, David. A produção capitalista do espaço. São Paulo: Annablume, 2006.

HOLLANDA, Ana. Discursos: 36a sessão do comitê do patrimônio mundial da Unesco. 2012. Disponível em: <http://www.cultura.gov.br/discursos/-/asset_publisher/DmSRakoYtQfY/content/36\%C2\%AA-sessao-docomite-do-patrimonio-mundial-da-unesco-532517/10883>. Acesso em: 7 maio 2016.

IPHAN. Unesco recebe dossiê da candidatura do Rio de Janeiro à lista do patrimônio mundial. 2011. Disponível em: $\quad$ <http://portal.iphan.gov.br/noticias/detalhes/1604/unesco-recebe-dossie-da-candidatura-do-rio-dejaneiro-a-lista-do-patrimonio-mundial>. Acesso em: 5 maio 2016.

KRÄTKE, Stefan. The new urban growth ideology of "creative cities". In: BRENNER, Neil; MARCUSE, Peter; MAYER, Margit. Cities for people, not for profit: an introduction. Londres, Nova lorque: Routledge, 2012. P. 138-149.

LOPES, Igor. Milagre econômico chega ao Rio e Câmara Portuguesa convoca investidores. Jornal Mundo Lusíada, 17 ago. 2012. Folha Economia. Disponivel em: <http://www.mundolusiada.com.br/economia/milagre-economico-chega-ao-rio-e-camara-portuguesaconvoca-investidores/>. Acesso em: 5 maio 2016.

MACEDO, Mirela Arcângelo da Motta. Projeto corredor cultural: um projeto de preservação para a área central do Rio de Janeiro (1979-1993). 2004. Dissertação (Mestrado) - Escola de Engenharia de São Carlos, Universidade de São Paulo, São Carlos, 2004.

MIGUEZ, Paulo. Economia criativa: uma discussão preliminar. In: NUSSBAUMER, Gisele Marchiori (Org.). 
Teorias e políticas da cultura: visões multidisciplinares. Salvador: EDUFBA, 2007. p. 95-113.

PINHEIRO, Augusto Ivan de Freitas. Aprendendo com o patrimônio. In: OLIVEIRA, Lúcia Lippi (Org.). Cidade: história e desafios. Rio de Janeiro: FGV, 2002. p.140-173.

REIS, Ana Carla Fonseca, et al. Economia criativa: um conjunto de visões. São Paulo: Fundação Telefônica, 2012 .

RIBEIRO, Luiz Cesar de Queiroz. Os desafios da reforma urbana nas metrópoles brasileiras. In: KLINK, Jeron. (Org.). Governança das metrópoles: conceitos, experiências e perspectivas. Pinheiros: Annablume, 2011.

RIO DE JANEIRO. Decreto n 23162, de 21 de julho de 2003. Institui o registro de bens culturais de natureza imaterial que constituem patrimônio cultural carioca e dá outras providências. Diário Oficial do Município do Rio de Janeiro, Rio de Janeiro, Poder Executivo, 2003.

. Decreto n०24677 de 28 de setembro de 2004. Cria o Grupo de Trabalho, no âmbito da Prefeitura da cidade do Rio de Janeiro, para sua indicação na lista do patrimônio mundial. Diário Oficial do Município do Rio de Janeiro, Rio de Janeiro, Poder Executivo, 2004.

. Decreto n$^{\circ}$ 30.339, de $1^{\circ}$ de janeiro de 2009. Dispõe sobre a organização básica do Poder Executivo Municipal. Diário Oficial do Município do Rio de Janeiro, Rio de Janeiro, Poder Executivo, 2009.

. Decreto n 35.879, de 05 de julho de 2012. Dispõe sobre o Rio como Patrimônio da Humanidade e dá outras providências. Diário Oficial do Município do Rio de Janeiro, Rio de Janeiro, Poder Executivo, 2012.

. Decreto no 4141 de 14 de julho de 1983. Aprova o PA 10.290 e o PAL 38.871 e fixa os limites da área abrangida pelo Corredor Cultural. Diário Oficial do Município do Rio de Janeiro, Rio de Janeiro, Poder Executivo, 1983.

Lei Complementar № 16, de 04 de junho de 1992. Dispõe sobre a política urbana do Município, institui o Plano Decenal da Cidade do Rio de Janeiro, e dá outras providências. Diário Oficial do Município do Rio de Janeiro, Rio de Janeiro, Poder Executivo, 1992.

Lei no 3.172, de 27 de dezembro de 2000. Cria e extingue Secretarias Especiais, Altera a denominação das atuais Secretarias Municipais de Trânsito e de Cultura e dá Outras Providências. Diário Oficial do Município do Rio de Janeiro, Rio de Janeiro, Poder Executivo, 2000.

Prefeitura Municipal. Plano estratégico da cidade do Rio de Janeiro: as cidades da cidade. Rio de Janeiro, 2004.

. Plano estratégico da cidade do Rio de Janeiro: pós-2016, o Rio mais integrado e competitivo. Rio de Janeiro, 2010

. Plano estratégico da cidade do Rio de Janeiro: Rio sempre Rio. Rio de Janeiro, 1996. 
SÁNCHEZ, Fernanda. A reinvenção das cidades para um mercado mundial. Chapecó: Argos, 2010.

Cidade espetáculo: política, planejamento e city marketing. Curitiba: Palavra, 1997.

UNESCO. Convenção para a proteção do patrimônio mundial, cultural e natural. Paris: UNIESCO, 1972.

UNESCO. Evaluations of cultural propertiers. Paris: UNESCO, 2003. Disponível em: < http://whc.unesco.org/archive/2003/whc03-27com-info8ae.pdf>. Acesso em: 5 maio 2016.

VAINER, Carlos. Pátria, empresa e mercadoria: notas sobre a estratégia discursiva do planejamento estratégico urbano. In: ENCONTRO NACIONAL DA ANPUR, 8., 1999, Porto Alegre. Anais... Porto Alegre: PROPUR - UFRGS, 1999.

WORLD HERITAGE COMMITTEE. Decisions adopted by the World Heritage Committee at its 36 th Session. São Petersburgo: World Heritage Committee, 2012. Disponivel em: <http://whc.unesco.org/archive/2012/whc1236com-19e.pdf>. Acesso em: 20 ago. 2012.

Recebido em 30/06/2014 - Aprovado em 08/01/2016. 